\title{
General Strategy for Fabrication of Ordered One Dimensional Inorganic Structures by Electrospinning: Structural Evolution From Belt to Solid via Hollow Tubes
}

\author{
Anitha Senthamizhan,* Brabu Balusamy,* Asli Celebioglu, and Tamer Uyar*
}

Super-structured hollow materials are the subject of intense research due to their attracting properties and diverse applications. Despite their significance, it still remains a crucial challenge to develop a simple and well-organized method to prepare the hollow tubes with controlled architectures. Herein, a general route to prepare structurally well-defined ID zinc oxide $(\mathrm{ZnO})$ structures by a single-spinneret electrospinning method coupled with thermal treatment is demonstrated for the first time and subsequently designated to identify highperformance materials for catalytic application. Two critical factors including tailoring the precursor amount and colloidal-stability of the precursor play critical role in tuning the structure precisely. The careful optimization of processing conditions enables chronological structural evolution from tubular to solid fiber structures composed of nanograins. These $\mathrm{ZnO}$ complex hollow structures showcase excellent photocatalytic performance; single nanograined wall hollow tubes manifest the high-catalytic performance over other samples with remarkable cycling stability. Benefitting from fabrication adaptability, different types of metal oxide hollow tubes are prepared that indicates the generality of the method. The proposed method postulates new insights for the development of electrospun hollow-structured fibers in a simple, cost-effective, and industrially feasible manner which holds apparent potential in many sectors.

\section{Introduction}

Increasing profound interest in methods to fabricate complex hollow superstructures in terms of shell architecture is highly

Dr. A. Senthamizhan, ${ }^{[+]}$Dr. B. Balusamy, ${ }^{[+]}$Dr. A. Celebioglu ${ }_{1}^{[+]}$

Prof. T. Uyar

Institute of Materials Science and Nanotechnology

UNAM-National Nanotechnology Research Center

Bilkent University

Ankara 06800, Turkey

E-mail: as3485@cornell.edu; bb626@cornell.edu; tu46@cornell.edu

Prof. T. Uyar

Department of Fiber Science and Apparel Design

College of Human Ecology

Cornell University

Ithaca, NY 14853, USA

The ORCID identification number(s) for the author(s) of this article can be found under https://doi.org/10.1002/adem.202001129.

${ }^{[+]}$Present address: Department of Fiber Science and Apparel Design, College of Human Ecology, Cornell University, Ithaca, NY 14853, USA

DOI: 10.1002/adem.202001129 desirable for the realization of various functionalities. Recent efforts in this direction have strongly suggested that unlike other hollow structures, tubular structures do not have well-developed nanostructure library, and establishing a general method remains a significant challenge. Hollowstructured metal oxides have emerged as one of the most propitious functional materials by virtue of their hollow interior, shell composition, internal structure, low density, high surface area, and fast diffusion ability. ${ }^{[1-4]}$ These solitary and exceptional characteristics have made them outstand in various fields including catalysis, chemical sensors, adsorption, and energy conversion/storage systems. ${ }^{[5-12]}$ The recent past has significantly seen dimensionally controlled structures to be drawing recognition because of their correlation between the structure and property in surfaceenhanced applications. In this aspect, intensive efforts have taken place to develop diverse approaches for assembling hollow structures to optimize their physicochemical properties for specific applications. Consequently, this has been upheld through varied synthesis routes and numerous hollow structures such as spheres, boxes, and micro/nanotubes have been fabricated. ${ }^{[13,14]}$

To raise the value of appropriate functionalities and exploit the structural advantages in surface-enhanced applications, welldefined shell structures with tunable size, shape, composition, and pores are highly desirable. However, most of the reported hollow structures possess relatively simple configuration which strongly limits their prospects to modulate potential characteristics. This remains as a substantial challenge to structural aspects including the shell thickness, number of internal multishells, porosity, and importantly unsuitable for large-scale synthesis. Among the different methods for preparing the hollow structures, template-assisted synthesis has been recognized as a straightforward method because of the predictability of the resultant shapes originating from the sacrificed templates. ${ }^{[15-18]}$ Although the templating strategy has enabled the successful preparation of hollow structures; however, it still possess few critical challenges. They include the cost, tedious and timeconsuming coating procedure, nonuniformity of coating, reproducibility, additional steps to remove the template without collapsing the original structure, and scalability. Furthermore, the 
extensive controlling natures of shell structures are limited to their parent templates. Altogether, this is a major drawback when used extensively and is more limited to academic knowledge rather than practical scale-up. In comparison to the methods already known for synthesis of hollow structures, approaches for the fabrication of 1D fibrous hollow materials have been limited. ${ }^{[19,20]}$ Notably, tubular nanostructures have been considered as special 1D structure, inheriting traits from both hollow and 1D structures.

Significant attention has been drawn toward electrospinning for producing 1D hollow tubular structures over other techniques attributable to easy fabrication, simple nature, distinct fibrous structures, tailored constitution, high reproducibility, cost-effectiveness, and industry-viable technology. ${ }^{[21-30]}$ This method along with different post-treatments has been applied to synthesize some fascinating surface-enhanced structures, but most of them have been limited to solid nanowires rather than nanotubes. ${ }^{[31-35]}$ The three main strategies include 1) fiber template, 2) coaxial, and 3) single-spinneret method. These methods have been adopted for making hollow structures, among which the single-spinneret approach has been a spellbinding topic of interest. Significantly, although various metal oxide hollow tubes have been prepared by electrospinning, controlled shell architectures have been rarely noticed. The development of a simple strategy for taking them on a larger scale with ease has still been unrealized. Therefore, it would be highly desirable to develop a simple and general strategy to effectively prepare the hollow tubes with complex architectures, but it is considered to be a challenging task.

Recent research efforts have found a strong correlation between the performance and shell-structure of hollow materials. For example, Peng and co-workers reported carbon templateassisted synthesis of spinel transitional metal oxide hollow structure with a unique necklace-like multishell for efficient water hydrolysis. ${ }^{[36]}$ The results have shown that the exceptional structures exhibit outstanding performance on the electrocatalytic activity for both hydrogen and oxygen evolution reactions because of higher active surface areas, superior mass, and charge transport. Recently, Chen et al. showcased the fabrication of multishell hollow metal/nitrogen/carbon dodecahedrons (metal@NC) in a controlled manner based on the combined approach of crystal growth and pyrolysis in a step-by-step manner. ${ }^{[37]}$ The increased shell number in the hollow Co@NC dodecahedrons displays an improved catalytic activity for the selected biomass derived hydrogenation process of furfural to cyclopentanol when compared to their solid and single-shell counterparts. Previously, our group has evinced the fabrication of metal oxide hollow tubes by adopting the atomic layer deposition (ALD) technique. This involved the coreshell structures were initially produced and later transformed to hollow structures either through water or thermal treatment based on the characteristics of the core polymer. ${ }^{[15,16]}$

Regardless of the progressiveness, challenges still pave the way in the controlled synthesis of hollow tubes. To the best of our knowledge, existing literature documents have no mention of the controlled fabrication of hollow structures and their functionalities depending on the special structures. Superstructured hollow materials display synergistic characteristics due to ensembles of nanoparticles that embrace collective properties which are individually shown by the nanoparticles. Furthermore, in practical applications, nanoparticles pose the concerns of aggregation that may result in diminishing performance. Interestingly, super-structured hollow materials are contemplated to outperform nanoparticle-assembled hollow architectures with much-amplified performance.

Influenced by the functionalities of hollow tubes related to their shell wall structures, we have made an endeavor to construct hollow tubes in a well-controlled manner. These can be used to recognize and draw linear answers to their properties. In this article, we present a simple, straightforward, and general strategy based on single-spinneret electrospinning followed by a pyrolysis process in air to prepare the metal oxide hollow tubes with well-defined shell wall structure. To be more precise, we have pioneered a new version of polymeric templating, based on the colloidal stability of metal ion-polymer precursors for the first time, to the best of our knowledge. Interestingly, the structure of the samples can be effectively tuned from 1D belt to hollow tubes and then to solid structures. The shell structures have been effectively controlled by the metal ion loading, and the proposed approach is tuned to be universal and has been successfully tested on an extensive range of metal oxide materials. In general, the arrays of particles in the shell wall structure of hollow tubes lack the intrinsic properties of unique nanocrystals. The proposed approach has swamped their disadvantages by controlling the grains and interface, retaining their collective characteristics and even more.

Stimulating developments have been observed in this approach, and extended to the preparation of various inorganic metal oxide hollow tubes. The hollow-structured materials can be anticipated to dramatically benefit surface-related applications, such as gas sensing, catalytic, adsorption, and etc. In this context, the correlation between hollow structures and their photocatalytic performance has been well studied and discussed. The observed results have manifested the evident distinctions in the catalytic performances in accordance with the structures. The single-walled hollow tubes displayed superior photocatalytic performance as a result of nanograin formulated single-wall structural integrity and numerous grain boundaries which proved to be an advanced material. On a final note, we would like to emphasize on the need for a technology that can be possibly applied to a larger scale preparation and reproducible in nature. On this context, the proposed approach has been shown to be a simple and powerful one that does not involve a complex procedure and can be possibly applied at a larger scale.

\section{Results and Discussion}

\subsection{Preparation, Morphology Evolution and Physicochemical Properties of Electrospun $\mathrm{ZnO}$}

Our approach adopts a simple two-step procedure for the fabrication of hollow tubes, wherein a single-spinneret electrospinning approach has been used for the preparation of composite fibers and subsequently converted to hollow structures by calcination under air atmosphere. A natural question thrusts here on the conditions for formation of hollow tubes. An enormous 
intensive research reports have been already demonstrated the impact of annealing parameters including heating rate/temperature on the fiber morphology and their consequent performance. ${ }^{[19]}$ Primarily, the morphological features of bare poly(methyl methacrylate) (PMMA) fibers have been studied using scanning electron microscope (SEM), and the observation has revealed that the as-spun pristine PMMA fibers exhibit an uniform and smooth surface with a diameter of $819 \pm 0.084$ $\mathrm{nm}$ and the close observation of broken fibers indicated their solid nature as shown in Figure S1, Supporting Information. In this aspect, the effect of colloidal stability between polymer and metal ions on the formation of hollow tubes has been well studied over a wide range of time period and the corresponding results have shown that $48 \mathrm{~h}$ time period is an optimal condition required for ideal preparation. To examine this effect, we have spun the PMMA/zinc acetate solution without allowing deep impact on the colloidal stability and further used in the preparation of the composite fibers which have been then subjected to calcination in air at $500{ }^{\circ} \mathrm{C}$ to remove the polymeric template. This resulted in thorough collision of fibrous structure and the formation of $\mathrm{ZnO}$ sheets composed of nanoparticles as shown in Figure S2, Supporting Information. In a typical process, the optimized time period stabilizes the inorganic metal ions due to the existences of coordination with polymeric network which led to the controllable assembly and homogeneous distribution of metal ion precursor.

A detailed investigation regarding influence of concentration of the metal ion precursor on the assembly of hollow tubes has been performed. To address the impact of precursor solution on the size of resultant fibers, quantitative analysis has been performed by measuring the diameter of the nanofibers from their SEM images as shown in Figure S3, Supporting Information, and calculated the mean diameter with corresponding standard error for each sample, and shown in Figure S4, Supporting Information. The corresponding results clearly indicate gradual increases in fiber diameter from $0.928 \pm 1.128$ to $2.138 \pm 0.385 \mu \mathrm{m}$ with increasing the zinc acetate concentration from 0.2 to $2.0 \mathrm{wt} \%$ as compared to bare PMMA fibers. Consequently, we have also noticed that the standard error of the mean diameter of the electrospun fibers increases due to the nonuniform ejection of the jet. Notably, surface roughness of the composite fibers has been increased compared to bare PMMA fibers.

The composite fibers were further subjected to calcination in air at $500{ }^{\circ} \mathrm{C}$ to remove the polymeric template. The X-ray diffraction (XRD) spectra have been used to confirm the formation of $\mathrm{ZnO}$ in all samples, and the peaks correspond to (100), (002), (101), (102), (103), (110), and (112) planes indexed as hexagonal wurtzite ZnO structure (JCPDS file no. 36-1451) as shown in Figure S5, Supporting Information. ${ }^{[38,39]}$ Moreover, no diffraction peaks attributed to any impurities have been detected. The surface and cross-sectional morphology of the calcined samples confirms the formation of belts, hollow tubes, and solid fibers as shown in Figure 1 and the images evidently indicate that the representative structures are highly uniform. Interestingly, the removal of polymeric template during calcination process has not destroyed the 1D structure of the fibers. The shell wall of hollow tubes comprised of nanoparticle that has been further turned to transform as small segments of nanofibers at higher concentrations which resulted in the formation of shell wall consisting of nanofibers as shown in Figure $1 d_{2}-d_{4}$ Interestingly, no evidences of cracks and defects along the direction of the hollow tubes have been observed. It is evidenced that the diameter of each hollow tube became higher as compared to their corresponding composite fibers (please refer to Figure S6 Supporting Information) and the fibers are well presented without significant agglomeration. Based on these findings, the obtained hollow structures own the advantages of both micro and nanometer-scaled building blocks which are fairly called as super-structured hollow tubes hereafter.

The observed results have been well evidenced that the adopted strategy effectively tuned the surface topography of shell wall by simply changing the precursor concentration. To attain further insight into the morphological features of each sample, a closer examination of outer and inner surface has been performed. As shown in Figure S7, Supporting Information, the closer examination revealed that both the surfaces of all the structures composed of nanograins that are uniform, regular in size $(20-30 \mathrm{~nm})$, interconnected to each other, and the shell wall of hollow tubes discloses highly porous texture. Especially, the formation of uniform fibers offers unique beneficial features in the fabrication of consistent hollow-structured $\mathrm{ZnO}$ tubes.

In detail, as shown in Figure $1 \mathrm{a}_{1}-\mathrm{a}_{4}$, the samples prepared at lower concentration exhibit belt morphology since the thin shell layer of $\mathrm{ZnO}$ nanograins is not able to preserve the hollow structure thus leads to collapse the shell into nanobelt morphology during the calcination process. Further increasing the precursor concentration to $0.4 \%$ resulted in the formation of hollow tubes with single-layered grains and the structure of shell displayed wavy surfaces hereafter referred as single-shell walled hollow tubes (ZSWHTs) as shown in Figure $2 \mathrm{a}_{1}-\mathrm{a}_{4}$. To the best of knowledge, this study represents the first observation on obtaining the single-walled metal oxide hollow tubes assembled with nanograins via electrospinning approach. It is certain that the single-walled hollow tubes possess the most salient advantages of the grain boundary effect compared to other structures.

As shown in Figure $1 d_{1}-d_{4}$ and Figure $S 7 d_{1}, d_{2}$, Supporting Information, the shell is constructed of particle-packed fibrous structure when concentration has reached to $1.0 \mathrm{wt} \%$ and interestingly observed the same on both surface. In the case of very high concentration (i.e., $2 \mathrm{wt} \%$ ), the solid fibers are formed and composed of small segments of fibers consisting of nanoparticles. As a proof of concept, it is obvious that the morphological evolution is closely associated to the changes in the concentration of the zinc acetate in the fibers. To further confirm these observations, transmission electron microscopy (TEM) analysis has been performed and the corresponding findings revealed that the structural evolution of electrospun derived fibers changes gradually from belt morphology to hollow tubes, and then finally turned to solid tubes at highest concentration as shown in Figure 2. Especially, thickness of the shell of tubes found to increase from about $15 \mathrm{~nm}$ to $90 \mathrm{~nm}$ upon consistently increasing the zinc acetate concentration from 0.2 to $2 \% \mathrm{w} / \mathrm{v}$. Overall outcomes suggest that the hollow tubes can be attained with excellent control over the shell thickness.

These findings specified that the amount of precursor played vibrant role in controlling the architecture of hollow tubes. 


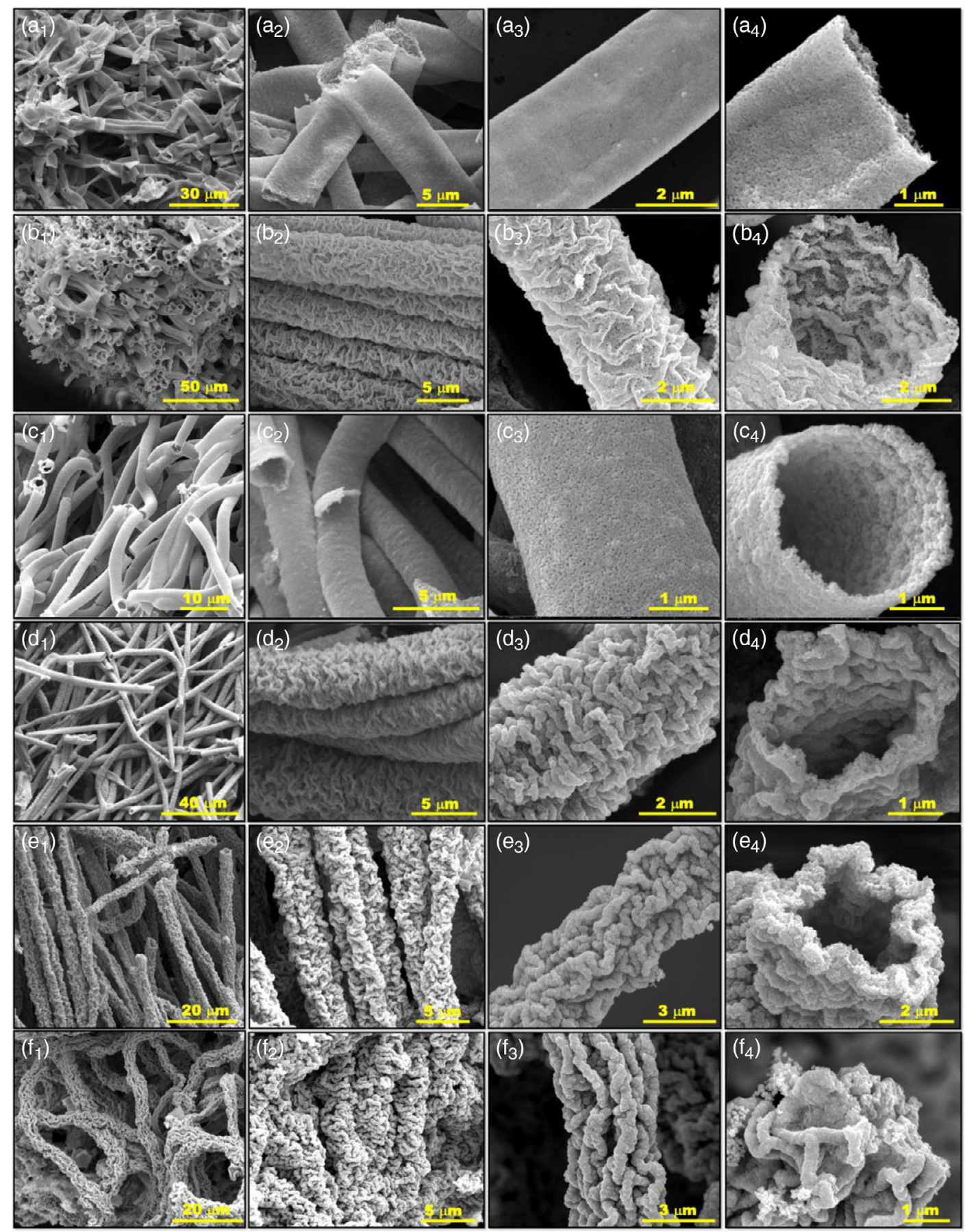

Figure 1. Morphological evolution of $\mathrm{ZnO}$ structures. $\mathrm{a}_{1}-\mathrm{f}_{4}$ ) Representative SEM images of $\mathrm{ZnO}$ with multilevel architectures under different magnifications. The pyrolysis of PMMA/ZnAc composite fibers produces different structures from belt to solid tubes. The single $\mathrm{ZnO}$ structure displaying the hollow and solid nature, $\left.\left.a_{1}-a_{4}\right) Z B, b_{1}-b_{4}\right)$ ZSWHT, $\left.c_{1}-c_{4}\right)$ ZHT-2, $\left.d_{1}-d_{4}\right)$ ZHT-3, $\left.e_{1}-e_{4}\right)$ ZHT-4, and $f_{1}-f_{4}$ ) ZST.

Further investigations have been directed with varying diameter of the fibers by using different spinneret needle diameter at a definite precursor concentration $(0.5 \mathrm{wt} \%)$ to understand the hollowing process and the results have been examined carefully. The observed results are shown in Figure 3, which suggests that the hollowing process is highly coupled with diameter of the fibers at determined concentration. Given the notable observation on the outcome, approximately onefold increase in the fiber diameter resulted in belt morphology from the hollow tubes (please refer to Figure $3 b, c)$.

From these observations, we hypothesize that the structural evolution from belts to hollow tubes has been precisely controlled 


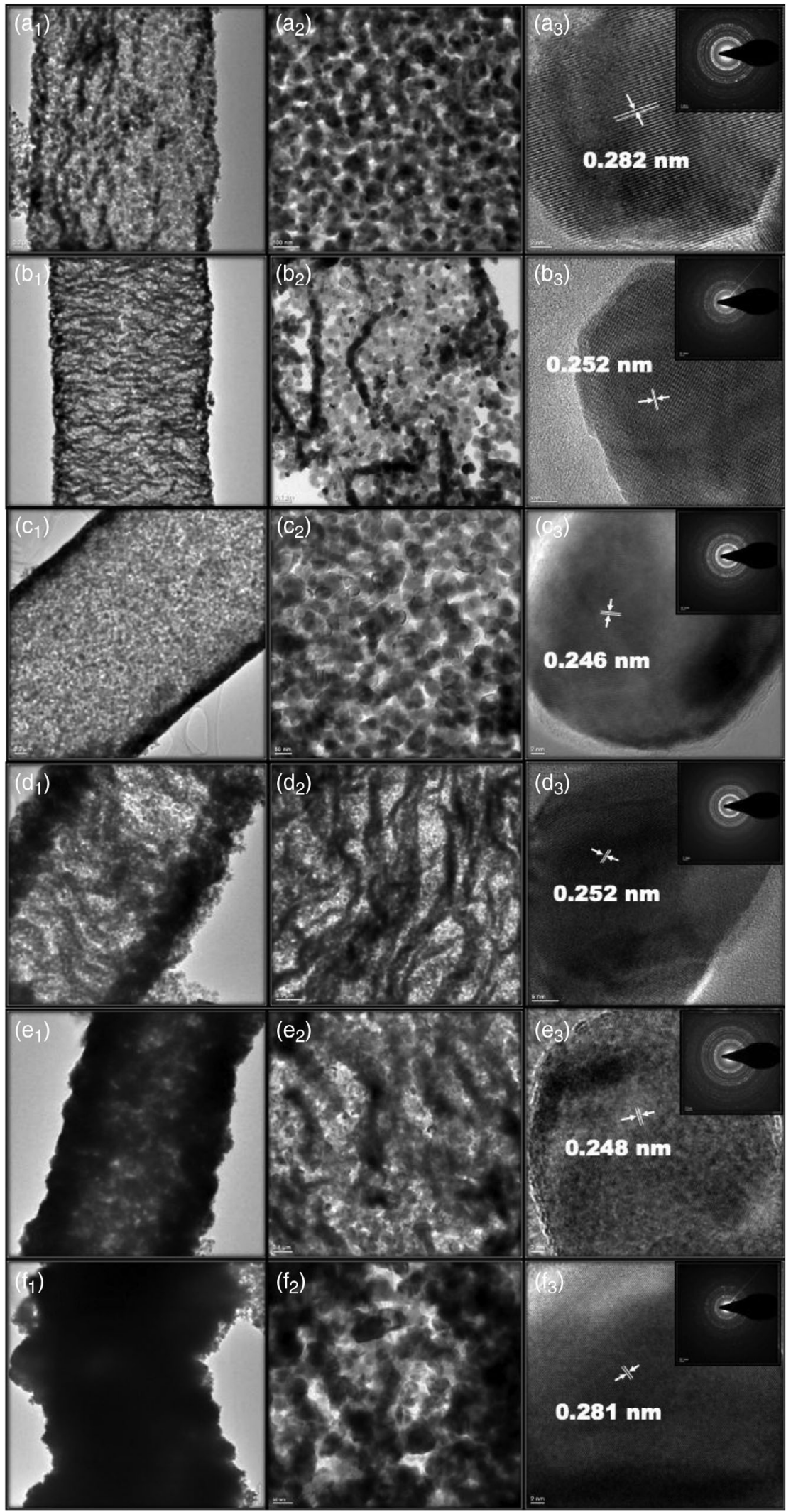

Figure 2. $a_{1}-f_{2}$ ) TEM images and $a_{3}-e_{3}$ ) HRTEM images of $\mathrm{ZnO}$ structures. The enlarged HRTEM image showing that the fibers are formulated by $\mathrm{ZnO}$ nanoparticles. The inset is the corresponding selected area electron diffraction pattern. 


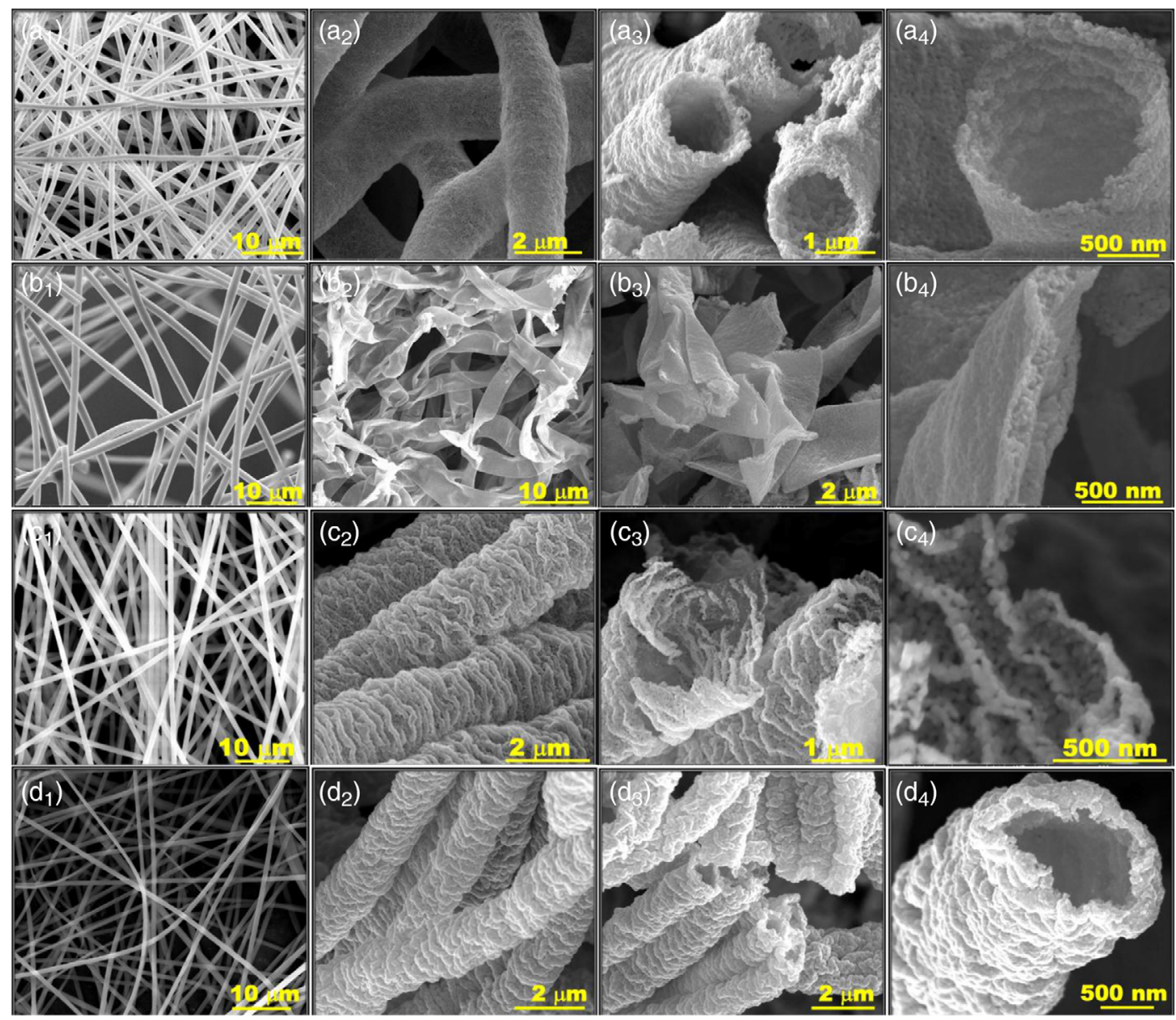

Figure 3. Morphological investigation of the electrospun $\mathrm{ZnO}$ hollow tubes. $a_{1}-d_{1}$ ) Representative SEM images of the as-spun PMMA/ZnAc fibers and $\left.\mathrm{a}_{2}-\mathrm{d}_{4}\right) \mathrm{ZnO}$ hollow tubes formed by calcination of PMMA/ZnAc fibers in air for $3 \mathrm{~h}$ at $500^{\circ} \mathrm{C}$. al $\left.-\mathrm{a} 4\right) \mathrm{A} 0.9 \mathrm{~mm}$ needle diameter, $\mathrm{b}_{1}-\mathrm{b}_{4}$ ) $1.1 \mathrm{~mm}$ needle diameter, cl-c4) $0.6 \mathrm{~mm}$ needle diameter, and $\left.d_{1}-d_{4}\right) 0.8 \mathrm{~mm}$ needle diameter. The detailed morphological analysis represents the diameter-dependent formation of hollow tubes.

by the relative diffusion of the metal ions into the surface of the electrospun polymeric fibers that suggest the Kirkendall effect. ${ }^{[39-41]}$ The induced temperature gradient during the calcination process has led to the formation of $\mathrm{ZnO}$ at the outer shell and simultaneous mass transport from the inner core resulted in the formation of pores. The formation of solid fibers at highest zinc acetate concentration further complements the proposed mechanism. Therefore, the proposed strategy presented in this work is facile, easily reproducible, and can be possibly applied to a large scale.

To gain more insight into the oxygen vacancies in the $\mathrm{ZnO}$ samples, X-ray photoelectron spectroscopy (XPS) of elemental oxygen $(\mathrm{O})$ and zinc $(\mathrm{Zn})$ has been performed and the results are shown in Figure 4. As seen in the spectra, it is confirmed that the $\mathrm{Zn}$ spectrum has two intense peaks centered at binding energies of $\approx 1021.8 \pm 0.4 \mathrm{eV}$ and $1044.8 \pm 0.4 \mathrm{eV}$ are assigned to $\mathrm{Zn} 2 \mathrm{p}_{3 / 2}$ and $\mathrm{Zn} 2 \mathrm{p}_{1 / 2}$, respectively, for all samples. The spin orbit splitting $(\Delta S)$ of these two peaks is measured as $\approx 23 \mathrm{eV}$ indicated by arrows in all the samples that confirmed the existence of zinc atom is in the form of $\mathrm{Zn}^{2+}$ ions in the wurtzite $\mathrm{ZnO}$ crystal lattice which is very consistent with the standard value of $22.97 \mathrm{eV}$ (see Figure $4 \mathrm{a}$ ). The asymmetric $\mathrm{O} 1 \mathrm{~s}$ peaks are deconvoluted into three Gaussian peaks centered at $\approx 530.6,531.9$, and $532.8 \mathrm{eV}$ [denoted as $\mathrm{O}_{\mathrm{L}}$ (lattice oxygen), $\mathrm{O}_{\mathrm{V}}$ (oxygen defects), and $\mathrm{O}_{\mathrm{Ch}}$ (chemisorbed oxygen)] as shown in Figure $4 \mathrm{~b}$, which are attributed to oxygen bonded with the $\mathrm{Zn}^{2+}$ ions in $\mathrm{ZnO}$ crystal lattice, oxygen defects, and surface-adsorbed oxygen species, e.g., $\mathrm{H}_{2} \mathrm{O}, \mathrm{OH}, \mathrm{O}^{-}$, and $\mathrm{O}^{2-}$, respectively. ${ }^{[38,42,43]}$ Indeed, the changes in the intensity of the peak $\mathrm{O}_{\mathrm{V}}$ might be associated with the changes in the concentration of oxygen vacancies. In addition, oxygen vacancies are known to affect the luminescence properties and certainly act as active sites for catalytic reaction, ${ }^{[20,44-46]}$ thereby improving the performance. As perceived in spectra, the content of $\mathrm{O}_{\mathrm{V}}$ in ZSWHT displays the substantial increase as compared with that of $\mathrm{ZnO}$ belt (ZB), suggesting that interfaces at the grains generate more oxygen vacancies as observed by their morphological features. The $\mathrm{O}_{\mathrm{V}}$ reduces in $\mathrm{ZnO}$ hollow tube (ZHT2) as compared to ZSWHT and then increases; however, comparing with all other samples, the ZSWHT and ZHT3 show the higher content of $\mathrm{O}_{\mathrm{V}}$. 

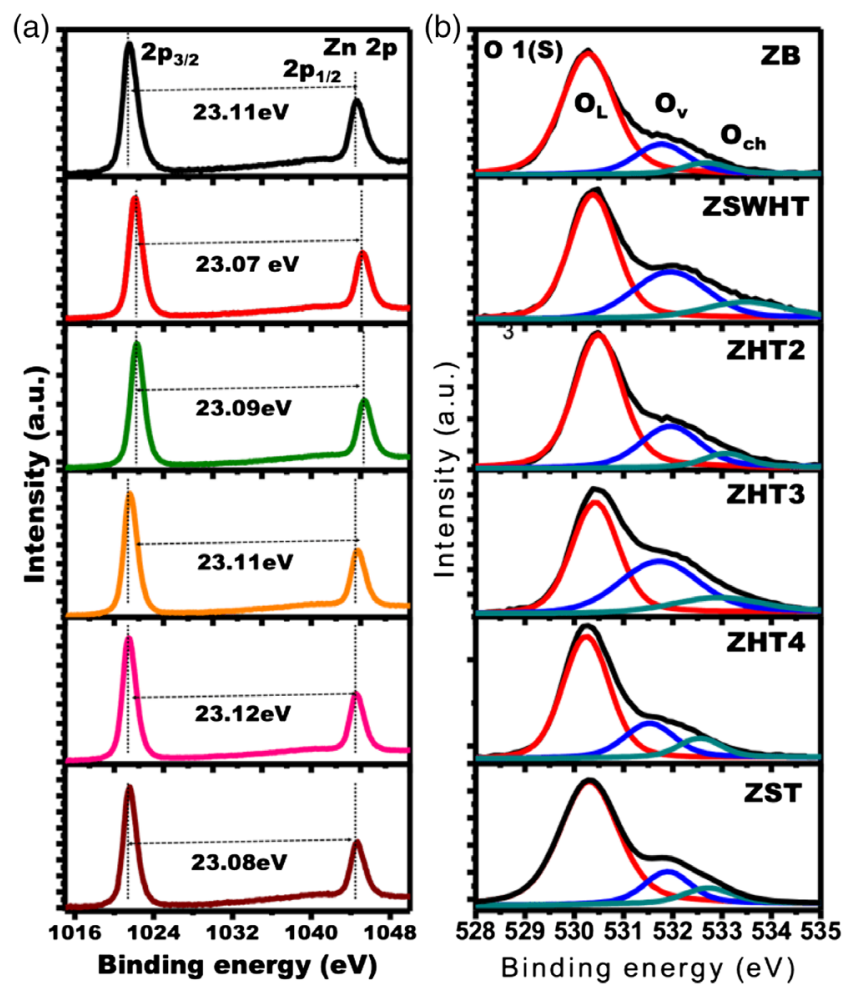

Figure 4. High-resolution XPS spectra of the a) Zn $2 p$ and b) O 1s orbitals from various electrospun $\mathrm{ZnO}$ structures. The attained spectrum is comprised of multiple peaks and deconvoluted into three peaks representing the presence of three different oxygen species denoted lattice oxygen $\left(\mathrm{O}_{\mathrm{L}}\right)$, oxygen vacancies $\left(\mathrm{O}_{\mathrm{V}}\right)$, and chemisorbed oxygen species $\left(\mathrm{O}_{\mathrm{Ch}}\right)$.

\subsection{Investigations on Structure-Photoluminescence Property Correlation}

The existence of defects has been well identified to influence the performance of $\mathrm{ZnO}$, and for that reason, the presence of intrinsic defects and their variation with respect to their shell wall structure is required to tune their performance in our case at present. The photoluminescence (PL) spectra of all the samples at an excitation wavelength of $325 \mathrm{~nm}$ were recorded and the representative spectra have been shown in Figure 5a-f. It has been noted that the luminescence spectra consist of strong and sharp near-band-edge (NBE) emission and the broad deep level of trapstate emission (DEB) in the visible region. The former peak occurred in the range of $382-385 \mathrm{~nm}$ for all samples is attributed to the exciton transitions and later assigned to the deep level of the trap-state emission band which emphasizes the presence of structural defects. And also, as confirmed by the XRD spectra, we strongly assume that the visible emission might be due to the intrinsic defects and not from any impurities.

A deeper examination foreseen that the broad DEB can be the superimposition of various emissions including violet, blue, green and orange-red emission representing different types of defects in the electrospun $\mathrm{ZnO}$ structures. ${ }^{[44-52]}$ The defects are expected to act as charge traps in the nanostructured sample and they are strongly associated with the nature of the defect center. Although tremendous efforts have been shed light on the correlation between the structure and energetic center of these defects, still their precise emission nature at room temperature remains under dispute. To date, accountable progresses have been made on such defects and their position in $\mathrm{ZnO}$ including oxygen vacancies $\left(\mathrm{V}_{\mathrm{O}}\right)$, zinc vacancies $\left(\mathrm{V}_{\mathrm{Zn}}\right)$, zinc interstitials $\left(\mathrm{Zn}_{\mathrm{i}}\right)$ interstitial oxygen $\mathrm{O}_{\mathrm{i}}$, and antisite oxygen $\mathrm{O}_{\mathrm{Zn}}$. Among them, the $V_{O}$ and $Z_{n_{i}}$ are donors whereas the $V_{Z n}, O_{i}$, and $\mathrm{O}_{\mathrm{Zn}}$ are acceptors. Notably, the types of defects and their concentrations are rationally associated to the changes in the emission intensity.

Closer insight into the spectra reveals that the observed emission is strongly correlated to the structure of hollow tubes. Based on the accountable research reports and theoretical calculations, the observed PL spectra were deconvoluted as shown in the Figure 5a-f and the schematic diagram shown in Figure $5 \mathrm{~g}$ shows each transition. The detailed peak fitting analysis has shown that the PL spectrum of each sample consists of six Gaussian bands. The intensity and energetic location of the defect-related emission might be associated with the variations of the intrinsic defects in ZnO hollow tubes. The existence of strong NBE denoted as B1 which reveals the high crystalline quality of the $\mathrm{ZnO}$ nanograins as evidently demonstrated previously by high-resolution transmission electron microscopy (HRTEM) and XRD. The observed slight shift in the NBE spectra might be resulted from the variation in the grain size. Interestingly, we have observed the defect-related band emission that has been varied with surface topography of the shell structure and the $I_{\mathrm{NBE}} / I_{\mathrm{DEB}}$ (defined as relative intensity of NBE to the DEB) ratio has been calculated as $1.99,0.47,1.29,0.73 .0 .44$, and 0.90 for ZB, ZSWHT, ZHT2, ZHT3, ZHT4, and ZnO solid tube (ZST), respectively. The observed highest values of $I_{\mathrm{NBE}} / I_{\mathrm{DEB}}$ for ZB as compared to ZSWHT highlighting the separated grains are well crystallized and have less grain boundaries at the interface of $\mathrm{ZnO}$.

The second Gaussian band denoted as B2 reveals the violet emission (VE) centered approximately at 395-400 nm (3.13$3.1 \mathrm{eV}$ ) originated from the recombination of the excited electrons from zinc interstitials $\mathrm{Zn}_{\mathrm{i}}\left(\mathrm{Zn}_{\mathrm{i}} \rightarrow \mathrm{VB}\right)$ with the holes in the valance band. In such case, the electrons from the conduction band transited to the $\mathrm{Zn}_{\mathrm{i}}$ state (shallow donor) located at $0.22 \mathrm{eV}$ below the conduction band through a nonradiative transition and then leads to emission as mentioned earlier. ${ }^{[4]}$ The third Gaussian band denoted as B3 represents the blue emissions (BEs) centered approximately at 450-468 nm (2.75-2.66 eV) originated from the recombination of the excited electrons from extended $\mathrm{Zn}_{\mathrm{i}}$ states $\left(\mathrm{ex}-\mathrm{Zn}_{\mathrm{i}} \rightarrow \mathrm{V}_{\mathrm{Zn}}\right.$ ) formed conferring to the defect ionization reaction $\left(\mathrm{Zn}^{*} \leftrightarrow \mathrm{Zn}_{\mathrm{i}}{ }^{+}+\mathrm{e}^{-1}\right)$ with the holes in $\mathrm{V}_{\mathrm{Zn}}$ state. Importantly, the designated states are well agreed to the full potential linear muffin-tin orbital method.

The green luminescence (GL) is subdived into two bands denoted as B4 and B5, with former one assigned to the photoexcited electron from $\mathrm{V}{ }^{*}$ o to the valence band $\left(\mathrm{V}{ }_{\mathrm{O}} \rightarrow \mathrm{VB}\right)$. Based on the studies and calculations, the observed emission band B5 $\left(\mathrm{CB} \rightarrow \mathrm{V}_{\mathrm{O}}{ }^{++}\right)$is due to the radiative recombination of an electron from the conduction band to deeply trapped doubly charged oxygen vacancy $\left(\mathrm{V}_{\mathrm{O}}{ }^{++}\right)$state formed by the grain boundary depletion region. The orange-red emission denoted as B6 centered approximately at $620-630 \mathrm{~nm}(2.0-1.96 \mathrm{eV})$ can be explained to the full potential linear muffin-tin orbital method, where it 
(a)

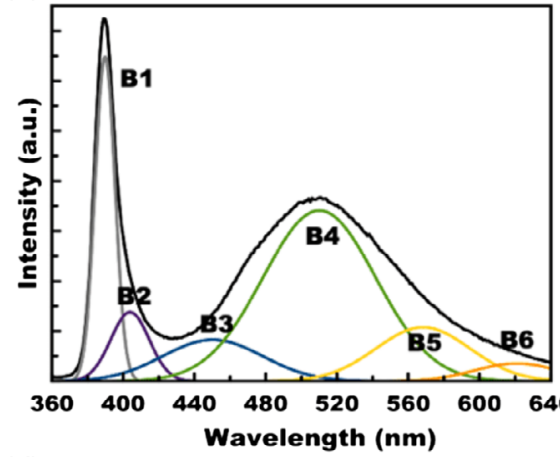

(d)

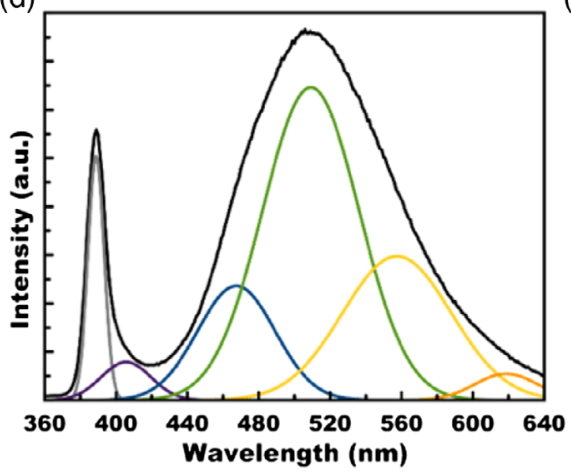

(b)

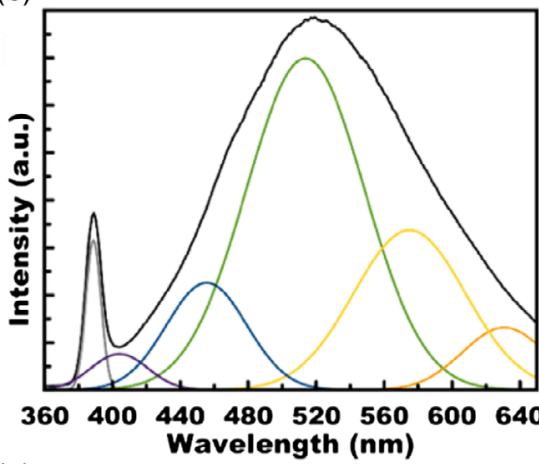

(e)

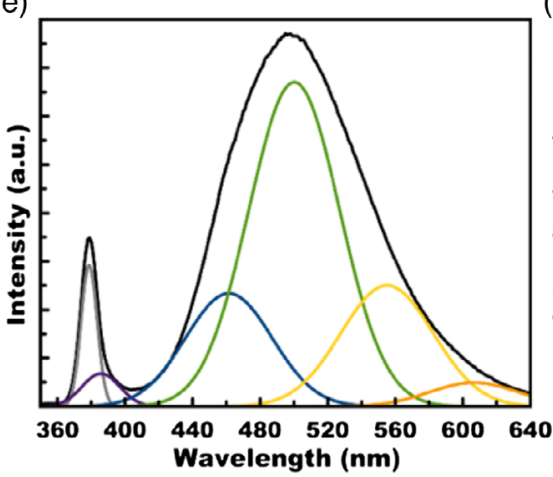

(c)

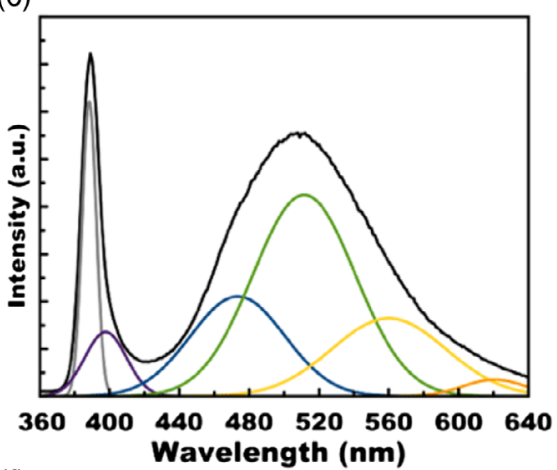

(f)

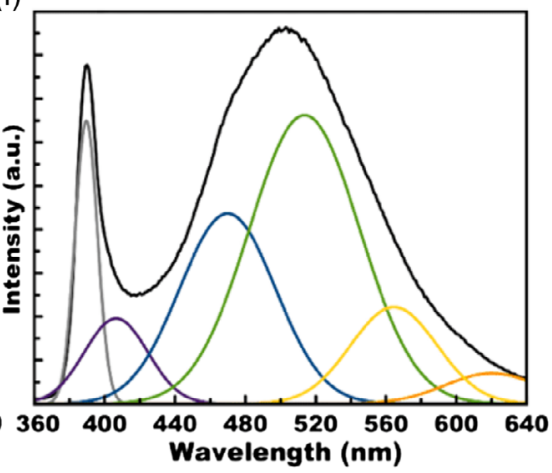

(g)

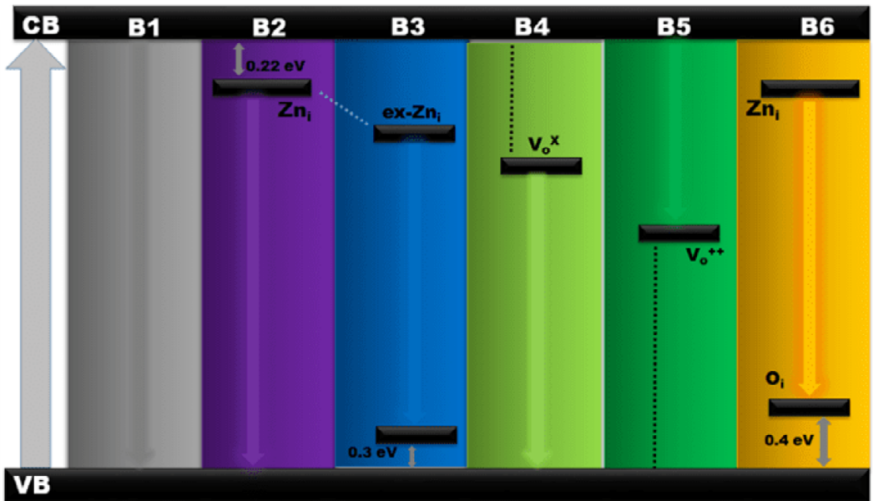

(h)

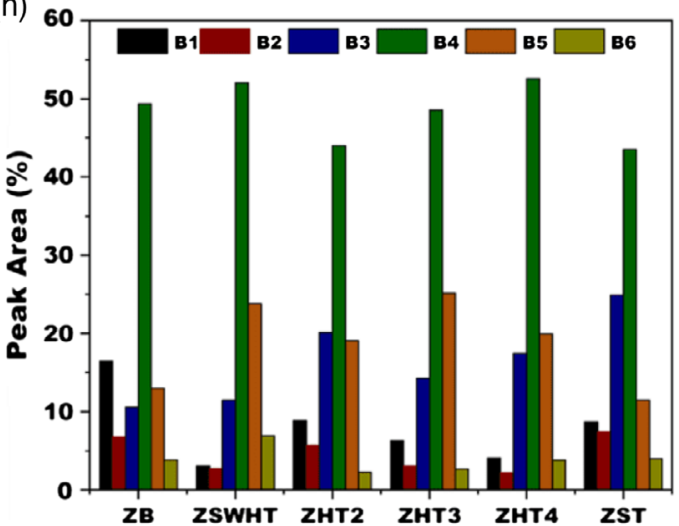

Figure 5. PL spectra of various electrospun ZnO structures. $\lambda e x=320 \mathrm{~nm}$. a) ZB, b) ZSWHT, c) ZHT-2, d) ZHT-3, e) ZHT-4, and f) ZST. The obtained spectra from electrospun $\mathrm{ZnO}$ structures are decomposed into six Gaussian peaks. g) Schematic band diagram describing the various defects and their associated emission. h) Peak area of each emission based on PL data.

is noted that $\mathrm{O}_{\mathrm{i}}$ level is located at $2.28 \mathrm{eV}$ below the conduction band, thereby deep level transition from the $\mathrm{Zn}_{i}$ to $\mathrm{O}_{\mathrm{i}}\left(\mathrm{Zn}_{\mathrm{i}} \rightarrow \mathrm{O}_{\mathrm{i}}\right)$ is possibly taken into the account. Overall, the predicted energetic location of each center is well agreed with theoretical calculations and various experimental results available in the literature so far. ${ }^{[44-52]}$

The detailed investigation predicted that the variations in the relative intensity of $\mathrm{ZB}$ to $\mathrm{ZST}$ might be ascribed to the presence of radiative defects at the interface of the grains in the $\mathrm{ZnO}$. The relative areas of each emission for all samples have been calculated and plotted in Figure 5h. Notably, the intensity of DEB has been increased in the case of ZSWHT as compared to ZB, wherein $\mathrm{B} 4\left(\mathrm{~V}^{*} \mathrm{O} \rightarrow \mathrm{VB}\right)$ and $\mathrm{B} 5\left(\mathrm{CB} \rightarrow \mathrm{V}_{\mathrm{O}}{ }^{++}\right)$emissions are found to be dominant. To have a comprehensive understanding, their morphological analysis is also taken into consideration where it is noted that the ZSWHTs consist of tiny grains, which are well connected and stacked together in an ordered manner without noticeable aggregation. The observation has shown that the presence of numerous grain boundaries greatly induces the grain boundary depletion that resulted in $\mathrm{V}_{\mathrm{O}}{ }^{++}$dominant emission. ${ }^{[20,53,54]}$

The relative intensity of NBE to the DEB for the ZHT2 is higher than the ZSWHT which implies that the grains are reasonably separated by well-formed pores and also the grains are highly crystallized. Considering the ZHT3, the DEB is increased as a result of increasing the shell wall thickness. Notably, as 
discussed previously, the small segmented fibers are facilitated more defect-related emission similar to the ZSWHT. At this moment, we should certainly compare the emission of the ZSWHT and ZHT3 to better understand the grain boundary effect and the corresponding results have shown that the well-ordered grains enabled more DEB. Considering the difference in the shell structure, the grains are intensely aggregated and irregularly arranged when the thickness of the wall increases which resulted in decreased content of defects-induced emission.

Overall, the attained results represented that the variations in the PL spectra of ZnO hollow tubes primarily associated to the shell wall structure assembled by nanograins and their interfaces, which determines the difference of the types and quantities of intrinsic defects in the hollow tubes and in the current system, the observed defects responsible for the visible emission are oxygen vacancies and $\mathrm{Zn}$ interstitials formed under O-rich conditions. More precisely, we have remarkably shown that the green emission can be effectually controlled by varying the shell wall thickness. The prominent effect greatly depends on the grain boundaries, which turn in to control the emission centers $\left(\mathrm{V}{ }^{*}, \mathrm{~V}_{\mathrm{O}}{ }^{++}\right)$and their concentration. In the coming section, we address how this type of defect and concentration help to enhance the photocatalysis of organic pollutants since the key mechanism of photocatalysis strongly depends on the chargecarrier generation, trapping, and recombination. The recent research reports have shown that the presence of defects in $\mathrm{ZnO}$ enhances the degradation abilities of organic pollutants as the defect centers can act as a scavenger that can effectively trap the electron or hole following the photoexcitation, consequently separate the charge carrier. Except to ZSWHTs of $\mathrm{ZnO}$, the other structures did not exhibit a similar trend for the photocatalytic degradation behavior. Based on the earlier understanding, we strongly speculate that the ZSWHT can be an effective photocatalyst as the grain boundary induced defects are expected to be more beneficial in addition to their structural features whereas the outweigh of $\mathrm{ZnO}$ shell layer its downsides.

\subsection{Photocatalytic Performance of Various Electrospun ZnO Structure}

Hollow-structured materials have been proved as an excellent catalyst, since their shell wall structures provide more accessible active sites and thus improve the utilization efficiency. The photocatalytic performances of electrospun $\mathrm{ZnO}$ super structures have been established by degradation of a typical model organic pollutant rhodamine $\mathrm{B}(\mathrm{RhB})$ in aqueous solution due to their extensive application as colorant in textile industries and their exposure leads to instigate several clinical complications, including carcinogenicity, reproductive toxicity, and neurotoxicity. ${ }^{[55,56]}$ Based on the observations previously showcased regarding the presence of pores on the shells, we anticipate that both the inner and outer surfaces of the hollow $\mathrm{ZnO}$ structures can play a significant role in the catalytic reaction that enhances the catalytic performance. It has been well proved in many cases that the surface structure and defects can also participate a significant role in improving the catalytic activity in addition to the higher surface area. To confirm the photodegradation is not caused by the self-photolysis, a dye sample without any catalyst was also simultaneously irradiated under same experimental conditions, and the results have shown that no significant degradation thereby it served as a control.

The influences of surface topographical features on the catalytic performance and the degradation efficiency indicated an order of ZSWHT $>$ ZHT3 $>$ ZHT2 $>$ ZB $>$ ZHT4 $>$ ZST have been clearly shown in Figure 6 . The ZSWHT with single-grained shell wall portrayed the highest performance with $\approx 98 \%$ dye degradation efficiency within $90 \mathrm{~min}$ irradiation period, whereas the ZST with solid morphological nature displayed lowest degradation efficiency $(\approx 22 \%)$ as shown in Figure $6 \mathrm{~b}$. The observed decrease in the photocatalytic activity of the ZST and ZB signifies the importance of hollow nature for promoting the photodegradation performances. The degradation efficiency of the remaining samples was determined to be $85 \%, 92 \%$, and $58 \%$ for the ZHT2, ZHT3, and ZHT4, respectively. As shown in Figure 6c, the $\mathrm{RhB}$ degradation data of electrospun $\mathrm{ZnO}$ structures obey pseudo first-order kinetic equation $\ln \left(C / C_{0}\right)=k t$, where $C_{0}$ and $C$ are the concentration of the RhB dye at the zero and at given time $t$, and $k$ is the degradation reaction rate constant $\left(\min ^{-1}\right)$. The apparent photodegradation rate $k$ is calculated to be $0.0456 \mathrm{~min}^{-1}$ for ZSWHT, which is about 3-fold $\left(0.0146 \mathrm{~min}^{-1}\right)$, 2.5-fold $\left(0.0181 \mathrm{~min}^{-1}\right), 1.7$-fold $\left(0.0267 \mathrm{~min}^{-1}\right)$, 5-fold $\left(0.0089 \mathrm{~min}^{-1}\right)$, and 17.5-fold $\left(0.0025 \mathrm{~min}^{-1}\right)$ higher than the ZB, ZHT2, ZHT3, ZHT4, and ZST, respectively (see Figure $6 \mathrm{~d}$ ). The recyclability studies performed using the ZSWHT revealed that their reusable potential for 15 cycles as shown in Figure 6e.

\subsection{Generality of the Method for Preparation of Various Hollow Tube Structure}

Further to explore universal nature of the proposed approach, we made an effort in the fabrication of different metal oxide hollow tubes including iron oxide $\left(\mathrm{Fe}_{2} \mathrm{O}_{3}\right)$, manganese oxide $\left(\mathrm{MnO}_{2}\right)$, copper oxide $(\mathrm{CuO})$, nickel oxide $(\mathrm{NiO})$, and composites $(\mathrm{CuO} / \mathrm{ZnO})$ under the same experimental conditions. The results are shown in Figure 7 and the corresponding observations revealed that the proposed method can be adopted in the fabrication of more other inorganic structures with different geometrics.

\section{Conclusion}

In summary, we have established a versatile strategy for the fabrication of diverse and complex $1 \mathrm{D} \mathrm{ZnO}$ structures ranging from belt to tubular and solid structures assembled by nanograins. The detailed investigation on time and concentration-dependent study of tubular formation confirms that an inside Kirkendall diffusion process is responsible for the hollow tube formation. The morphological features are well described and validated the formation of consistent shell thickness throughout the configuration. The proposed strategy owns abundant benefits in terms of structural flexibility, tunable porosity, hierarchical/multishelled structures, which would expect to greatly affect the properties. It is certain that the super structures of metal oxide drive 
(a)

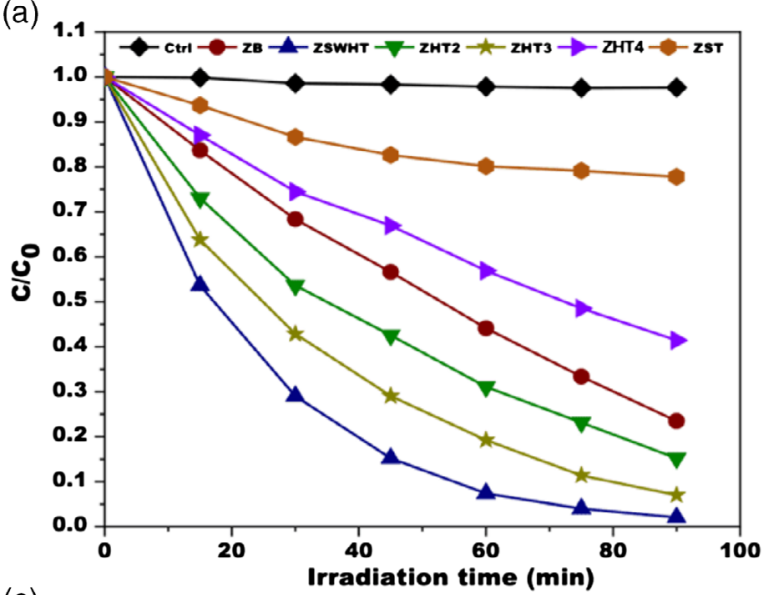

(c)

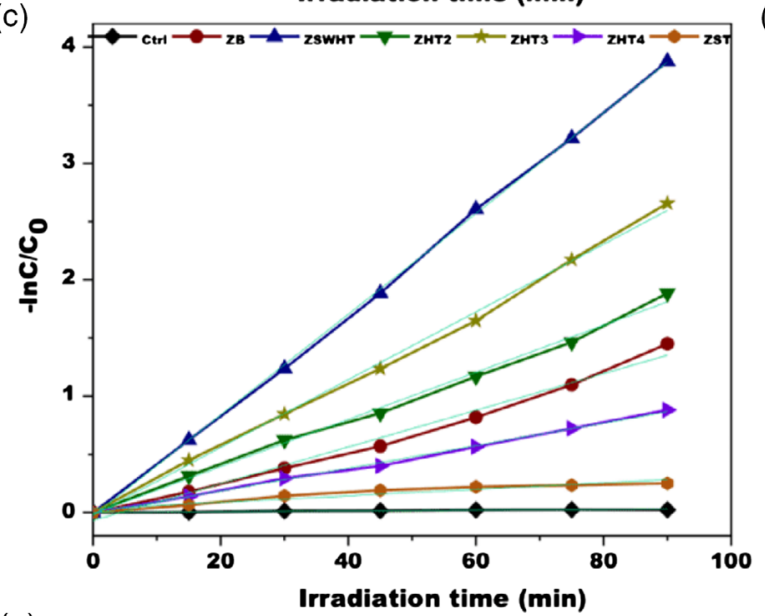

(b)

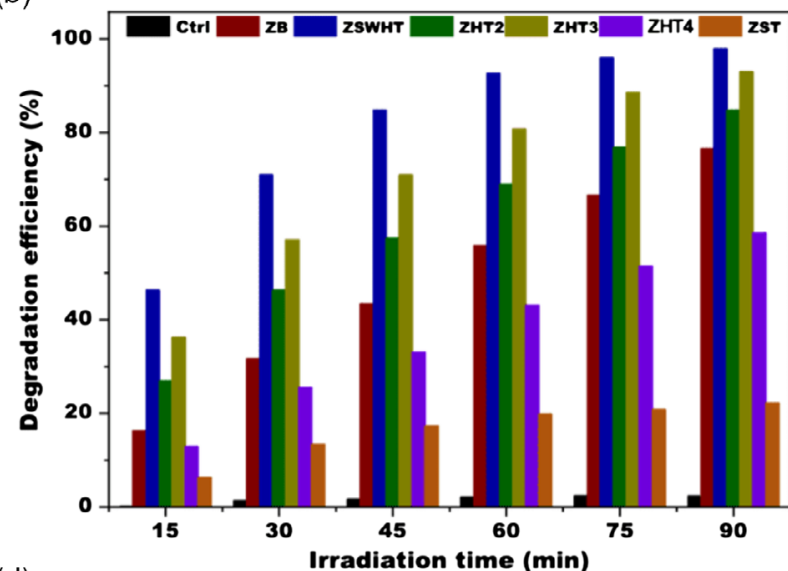

(d)

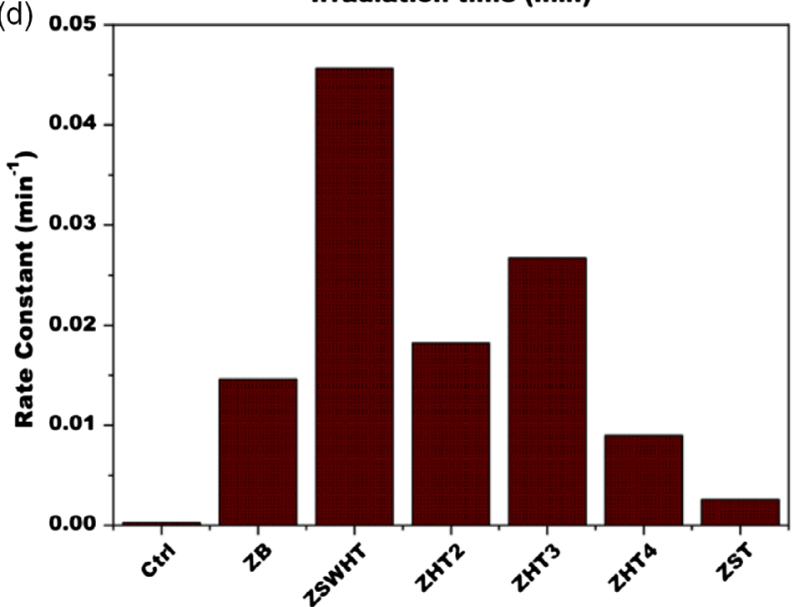

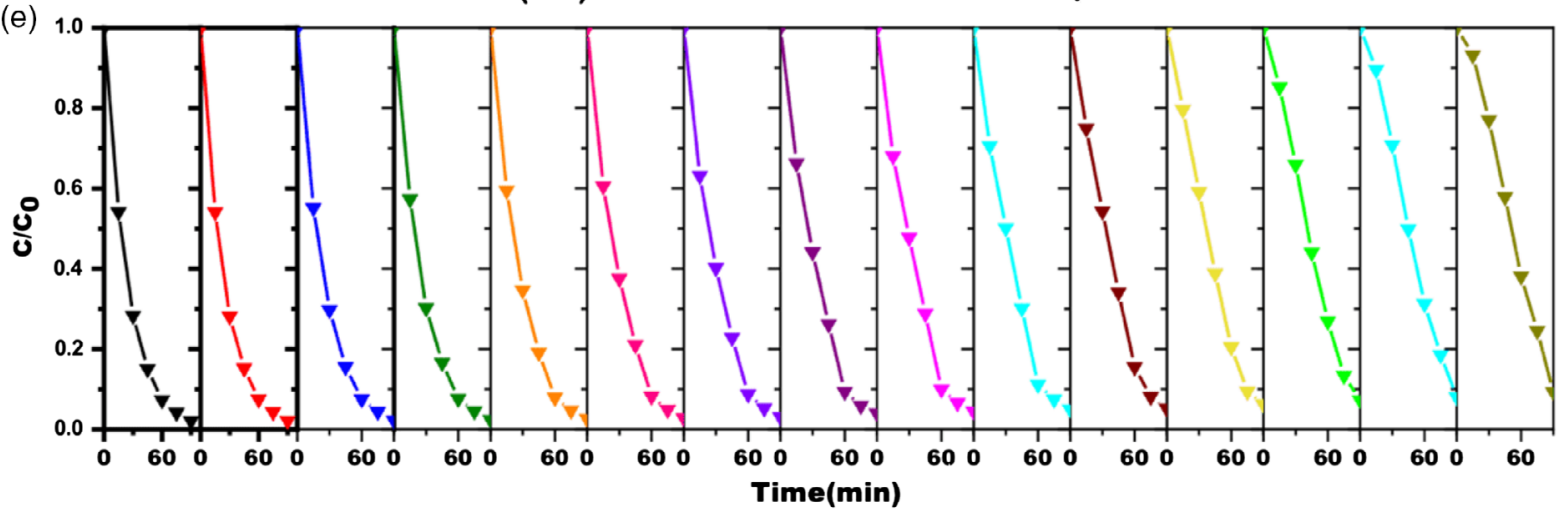

Figure 6. a) Morphology-dependent photocatalytic performance of various electrospun $\mathrm{ZnO}$ structures (blank: pure $\mathrm{RhB}$. $\mathrm{C}_{0}=10 \mathrm{mg} \mathrm{L}^{-1}$, catalyst$1 \mathrm{mg} \mathrm{mL}^{-1}$ ). b) Comparative degradation efficiency of RhB as a function of time in the absence and presence of different ZnO catalysts under UV light irradiation. c) The plot of $-\ln \left(C / C_{0}\right)$ versus irradiation time. $C_{0}$ and $C$ are the initial and final concentration of the RhB dye. The results are fitted using pseudo first-order kinetic equation. d) Rate constant and e) recycling performance of ZSWHT for 15 runs.

some prominent properties. The formation mechanism of such interesting library of structures might be attributed to the relative diffusion of the reactive species versus the diameter of the fiber. The morphological features can be certainly controlled by varying the processing parameters such as the amount of precursor and diameter of the fibers. As the amount of $\mathrm{Zn}^{2+}$ increases, the morphology of the obtained 1D $\mathrm{ZnO}$ changes from the belt superstructure assembled by nanoparticles and tubes to solid tubular structures. The approach reported here is facile, reproducible, and manufacturing scalability. The single-grained wall hollow tubes demonstrate the high-catalytic performance as well as superior cycling stability compared with the other structures might be mainly ascribed to their unique shell architectures. Our study can prove to be an effective general strategy for the rational design and precise preparation of hollow structures for various applications. 


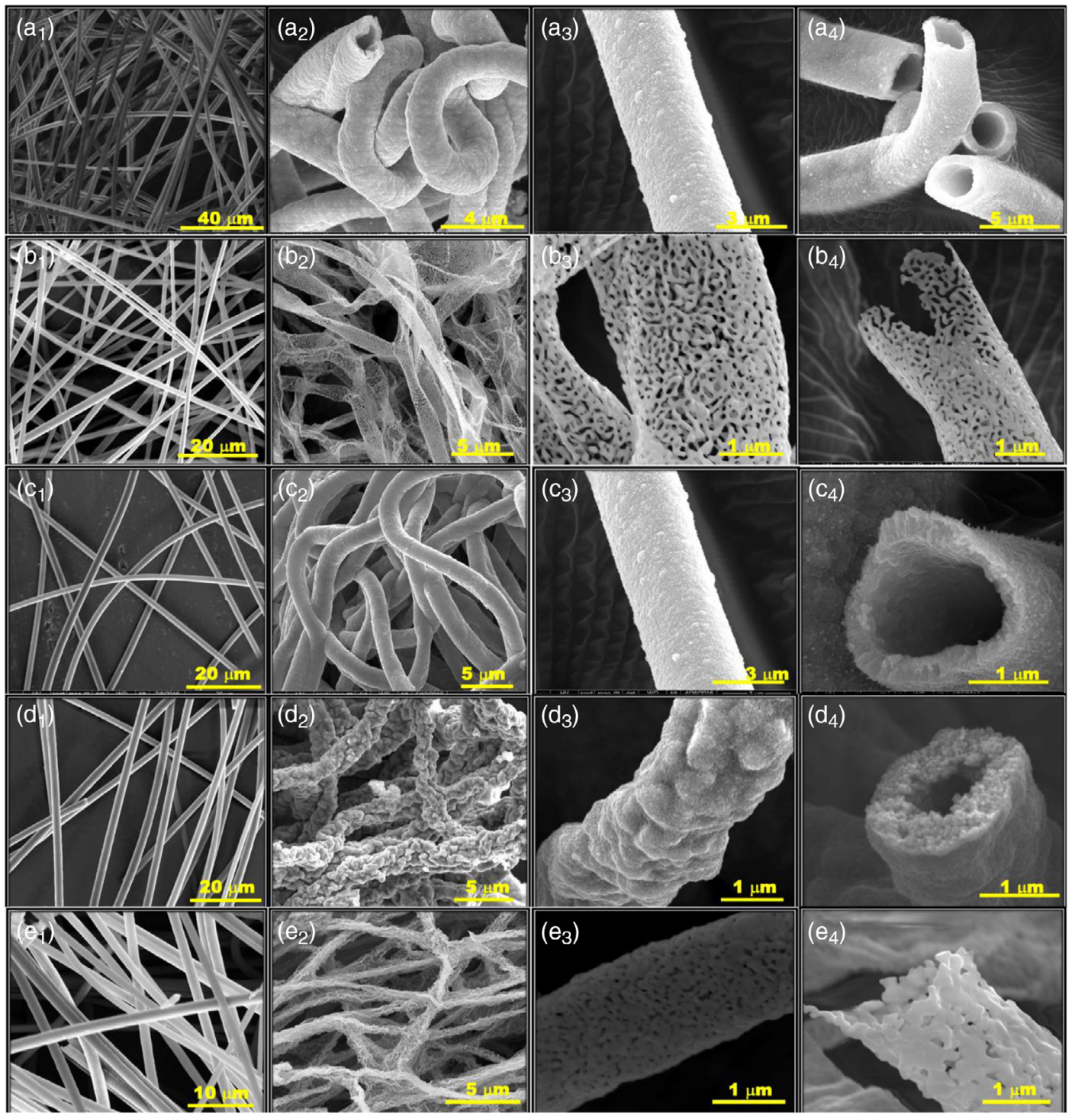

Figure 7. Morphological investigation of various materials produced by the versatile method. $\left.a_{1}-e_{1}\right) S E M$ image of polymeric composites fibers before calcination. $\left.\left.\left.\left.\mathrm{a}_{2}-\mathrm{a}_{4}\right) \mathrm{NiO}, \mathrm{b}_{2}-\mathrm{b}_{4}\right) \mathrm{MnO}_{2}, \mathrm{c}_{2}-\mathrm{c}_{4}\right) \mathrm{CuO}, \mathrm{d}_{2}-\mathrm{d}_{4}\right) \mathrm{CuO} / \mathrm{ZnO}$, and $\left.\mathrm{e}_{2}-\mathrm{e}_{4}\right) \mathrm{Fe}_{2} \mathrm{O}_{3}$.

\section{Experimental Section}

Materials: All the materials including dimethylformamide (DMF, 99\%), PMMA ( $\left.\mathrm{Mw} 350000 \mathrm{~g} \mathrm{~mol}^{-1}\right)$, zinc acetate dihydrate (reagent grade) and $\mathrm{RhB}(99 \%)$ were obtained from Sigma-Aldrich and used as received without any purification.

Electrospinning of $\mathrm{ZnO}$ Super-Structured Belt, Hollow, and Solid Tubes: For PMMA fibers, the uniform precursor solution for electrospinning was prepared by dissolving PMMA $(15 \%[\mathrm{w} / \mathrm{v}])$ in $\mathrm{DMF}$ at $50^{\circ} \mathrm{C}$ for $5 \mathrm{~h}$. In the case of $\mathrm{ZnO}$ structures, the precursor solutions were prepared by addition of different ratios of zinc acetate dihydrate to the DMF and then the PMMA (15\% [w/v]) was introduced following the complete dissolution of zinc acetate dihydrate and maintained at $50^{\circ} \mathrm{C}$ for $5 \mathrm{~h}$. To optimize the time period for colloidal stability between polymer and metal ions on the formation of hollow tubes, the polymeric precursor solution with $0.4 \% \mathrm{w} / \mathrm{v}$ of zinc acetate had been evaluated over a wide range of time period and found that $48 \mathrm{~h}$ time period was required for the successful preparation of hollow tubes. The attained viscous gel of PMMA/zinc acetate was referred to as spinning solution. Subsequently, the precursor solution was electrospun at a continuous flow rate of $\approx 0.5 \mathrm{~mL} \mathrm{~h}^{-1}$ (syringe pump: KDS-101, KD Scientific, USA) through a metallic needle with an inner diameter of $0.6 \mathrm{~mm}$ and applied high voltage of $10-12 \mathrm{kV}$ (Spellman, SL30, USA). The distance between the collector and injector nozzle was fixed as $13-15 \mathrm{~cm}$. The PMMA/zinc acetate composite nanofibers were collected on grounded stationary metal plate covered with aluminum foil. After the electrospinning process, the composite nanofibers were dried and calcined at $500^{\circ} \mathrm{C}$ in air for $3 \mathrm{~h}$ at a heating rate of $5{ }^{\circ} \mathrm{C} \mathrm{min}^{-1}$. The resultant calcined PMMA/zinc acetate composite nanofibers of $0.2 \%, 0.4 \%, 0.8 \%, 1.0 \%, 1.5 \%$, and $2.0 \% \mathrm{w} / \mathrm{v}$ concentrations had been analyzed for their morphological features and named accordingly as $\mathrm{ZB}, \mathrm{ZSWHT}$ ), ZnO hollow tube (ZHT2), $\mathrm{ZnO}$ hollow tube (ZHT3), ZnO hollow tube (ZHT4), and ZST, respectively.

Electrospinning of ZnO Super-Structured Belt, Hollow, and Solid TubesFabrication of Electrospun Superstructure ZB: In the case of super-structured 
ZB structure, the precursor solution was prepared by dissolving zinc acetate dihydrate $(0.2 \% \mathrm{w} / \mathrm{v})$ and PMMA $(15 \%(\mathrm{w} / \mathrm{v})$ in a solution of $\mathrm{N}, \mathrm{N}$ dimethylformamide (DMF) under magnetic stirring at $50^{\circ} \mathrm{C}$ for $5 \mathrm{~h}$. Then, the attained viscous gel of PMMA/zinc acetate was kept for $48 \mathrm{~h}$ at room temperature and referred to as spinning solution. Subsequently, the precursor was electrospun at a continuous flow rate of $\approx 0.5 \mathrm{~mL} \mathrm{~h}^{-1}$ through a metallic needle with an inner diameter of $0.6 \mathrm{~mm}$ applied high voltage of $12 \mathrm{kV}$. The electrospun composite fibers were dried and calcined at $500^{\circ} \mathrm{C}$ in air for $3 \mathrm{~h}$ at a heating rate of $5^{\circ} \mathrm{Cmin}^{-1}$.

Electrospinning of ZnO Super-Structured Belt, Hollow, and Solid TubesFabrication of Electrospun ZSWHT: In the case of ZSWHT, the precursor solution was prepared by dissolving zinc acetate dihydrate $(0.4 \% \mathrm{w} / \mathrm{v})$ and PMMA $\left(15 \%(\mathrm{w} / \mathrm{v})\right.$ in a solution of DMF under magnetic stirring at $50^{\circ} \mathrm{C}$ for $5 \mathrm{~h}$. Then, the attained viscous gel of PMMA/zinc acetate was kept for $48 \mathrm{~h}$ at room temperature and referred to as spinning solution. Subsequently, the precursor was electrospun at a continuous flow rate of $\approx 0.5 \mathrm{~mL} \mathrm{~h}^{-1}$ through a metallic needle with an inner diameter of $0.6 \mathrm{~mm}$ applied high voltage of $12 \mathrm{kV}$. The electrospun composite fibers were dried and calcined at $500^{\circ} \mathrm{C}$ in air for $3 \mathrm{~h}$ at a heating rate of $5^{\circ} \mathrm{C} \min ^{-1}$

Electrospinning of ZnO Super-Structured Belt, Hollow, and Solid TubesFabrication of electrospun ZHT2: In the case of ZHT2, the precursor solution was prepared by dissolving zinc acetate dihydrate $(0.8 \% \mathrm{w} / \mathrm{v})$ and PMMA $(15 \%(\mathrm{w} / \mathrm{v})$ in a solution of DMF under magnetic stirring at $50^{\circ} \mathrm{C}$ for $5 \mathrm{~h}$. Then, the attained viscous gel of PMMA/zinc acetate was kept for $48 \mathrm{~h}$ at room temperature and referred to as spinning solution. Subsequently, the precursor was electrospun at a continuous flow rate of $\approx 0.5 \mathrm{~mL} \mathrm{~h}^{-1}$ through a metallic needle with an inner diameter of $0.6 \mathrm{~mm}$ applied high voltage of $10 \mathrm{kV}$. The electrospun composite fibers were dried and calcined at $500^{\circ} \mathrm{C}$ in air for $3 \mathrm{~h}$ at a heating rate of $5{ }^{\circ} \mathrm{C} \mathrm{min}^{-1}$.

Electrospinning of ZnO Super-Structured Belt, Hollow, and Solid TubesFabrication of electrospun ZHT3: In the case of ZHT3, the precursor solution was prepared by dissolving zinc acetate dihydrate $(1.0 \% \mathrm{w} / \mathrm{v})$ and PMMA $(15 \%(\mathrm{w} / \mathrm{v})$ in a solution of DMF under magnetic stirring at $50^{\circ} \mathrm{C}$ for $5 \mathrm{~h}$. Then, the attained viscous gel of PMMA/zinc acetate was kept for $48 \mathrm{~h}$ at room temperature and referred to as spinning solution. Subsequently, the precursor was electrospun at a continuous flow rate of $\approx 0.5 \mathrm{~mL} \mathrm{~h}^{-1}$ through a metallic needle with an inner diameter of $0.6 \mathrm{~mm}$ applied high voltage of $11 \mathrm{kV}$. The electrospun composite fibers were dried and calcined at $500^{\circ} \mathrm{C}$ in air for $3 \mathrm{~h}$ at a heating rate of $5^{\circ} \mathrm{C} \mathrm{min}^{-1}$.

Electrospinning of ZnO Super-Structured Belt, Hollow, and Solid TubesFabrication of electrospun ZHT4: In the case of ZHT4, the precursor solution was prepared by dissolving zinc acetate dihydrate $(1.5 \% \mathrm{w} / \mathrm{v})$ and PMMA $(15 \%(\mathrm{w} / \mathrm{v})$ in a solution of DMF under magnetic stirring at $50^{\circ} \mathrm{C}$ for $5 \mathrm{~h}$. Then, the attained viscous gel of PMMA/Zinc acetate was kept for $48 \mathrm{~h}$ at room temperature and referred to as spinning solution. Subsequently, the precursor was electrospun at a continuous flow rate of $\approx 0.5 \mathrm{~mL} \mathrm{~h}^{-1}$ through a metallic needle with an inner diameter of $0.6 \mathrm{~mm}$ applied high voltage of $11 \mathrm{kV}$. The electrospun composite fibers were dried and calcined at $500^{\circ} \mathrm{C}$ in air for $3 \mathrm{~h}$ at a heating rate of $5^{\circ} \mathrm{Cmin}^{-1}$.

Electrospinning of ZnO Super-Structured Belt, Hollow, and Solid TubesFabrication of electrospun ZST: In the case of ZST, the precursor solution was prepared by dissolving zinc acetate dihydrate $(2.0 \% \mathrm{w} / \mathrm{v})$ and PMMA $\left(15 \%(\mathrm{w} / \mathrm{v})\right.$ in a solution of DMF under magnetic stirring at $50^{\circ} \mathrm{C}$ for $5 \mathrm{~h}$. Then, the attained viscous gel of PMMA/zinc acetate was kept for $48 \mathrm{~h}$ at room temperature and referred to as spinning solution. Subsequently, the precursor was electrospun at a continuous flow rate of $\approx 0.5 \mathrm{~mL} \mathrm{~h}^{-1}$ through a metallic needle with an inner diameter of $0.6 \mathrm{~mm}$ applied high voltage of $10 \mathrm{kV}$. The electrospun composite fibers were dried and calcined at $500^{\circ} \mathrm{C}$ in air for $3 \mathrm{~h}$ at a heating rate of $5{ }^{\circ} \mathrm{C} \mathrm{min}^{-1}$.

Electrospinning of ZnO Super-Structured Belt, Hollow, and Solid TubesFabrication of Various Electrospun Metal Oxide Hollow Tubes: The similar experimental condition with $0.5 \%$ of precursor concentration was used for different metal ions including iron oxide, manganese oxide, cobalt oxide, nickel oxide, and copper oxide/zinc oxide composites. In addition, we had prepared $0.5 \% \mathrm{w} / \mathrm{v}$ PMMA/zinc acetate composite nanofibers using different needles with various inner diameters including 0.6, 0.8, 0.9 , and $1.1 \mathrm{~mm}$ to have deeper insight on the effect of mechanism for the formation of hollow structure.

Characterization: The morphological and structural features of the $\mathrm{PMMA} /$ zinc acetate composite nanofibers and $\mathrm{ZnO}$ structures had been studied using field emission scanning electron microscopy (FESEM, Quanta $200 \mathrm{FEG}$ ) equipped with energy dispersive X-ray spectroscopy (EDX) and TEM (Tecnai G2 F30). The TEM analysis had been extensively used to investigate the hollow nature, $\mathrm{ZnO}$ nanograins, and lattice spacing. The crystalline phases had been characterized using PANalytical X'Pert Multipurpose X-ray diffractometer with $\mathrm{Cu} \mathrm{K} \alpha$ radiation. The defects in $\mathrm{ZnO}$ structures had been analyzed by $\mathrm{PL}$ measurements using timeresolved fluorescence spectrophotometer (FL-1057 TCSPC). XPS (Thermo K-alpha-monochromated) had been used to investigate the chemical composition. The degradation of dye pollutant had been monitored by recording the absorbance spectra using UV-Vis spectrophotometer (Varian Cary 100).

Photocatalytic Performance: The photocatalytic performance had been evaluated using the degradation competence of the prepared $\mathrm{ZnO}$ structures against $\mathrm{RhB}$ dye. The concentration of the catalyst and $\mathrm{RhB}$ had been fixed as $1 \mathrm{mg} \mathrm{mL}^{-1}$ and $10 \mathrm{ppm}$, respectively. Following the addition of the catalyst into aqueous dye solution, the samples had been placed in complete dark conditions for a time period of $30 \mathrm{~min}$ to establish absorption/ desorption equilibrium between the sample surface and dye prior to irradiation. During the catalytic process, the $\mathrm{ZnO}$ catalyst containing aqueous dye solution had been placed under UV irradiation (Ultra-Vitalux Ultraviolet high-pressure lamp, Osram, $300 \mathrm{~W}$, sunlight simulation) at a distance of $15 \mathrm{~cm}$. In a similar condition, a dye solution without the catalyst had been served as the control. The degradation rate of the dye pollutant had been continually monitored by recording the absorbance of the samples using a UV-Vis spectrophotometer on duration of every $15 \mathrm{~min}$. The characteristic peak of the RhB at $580 \mathrm{~nm}$ had been considered as a means of evaluating the degradation performance. The photocatalytic degradation efficiency of $\mathrm{RhB}$ had been determined by the formula $\left(\left(C_{0}-C\right) /\right.$ $\left.C_{0}\right) \times 100$ ), where $C_{0}$ and $C$ are the absorbance peak intensity before and after UV irradiation, respectively. In addition, the ZSWHT sample had been selected to evaluate the reusable proficiency for 15 consecutive cycles. This was because we had seen the highest photocatalytic performance compared to other prepared structures.

\section{Supporting Information}

Supporting Information is available from the Wiley Online Library or from the author.

\section{Acknowledgements}

A.S. and B.B. thank the Scientific and Technological Research Council of Turkey (TUBITAK) (TUBITAK-BIDEB 2216, Research Fellowship Programme for Foreign Citizens) for postdoctoral fellowship.

\section{Conflict of Interest}

The authors declare no conflict of interest.

\section{Keywords}

electrospinning, hollow tubes, nanograins, photocatalytic, single wall

Received: September 20, 2020

Revised: December 6, 2020

Published online: January 26, 2021 
[1] S. Dang, Q. L. Zhu, Q. Xu, Nat. Rev. Mater. 2018, 3, 17075.

[2] S. T. Riahinasab, A. Keshavarz, C. N. Melton, A. Elbaradei, G. I. Warren, R. L. B. Selinger, B. J. Stokes, L. S. Hirst, Nat. Commun. 2019, 10, 894

[3] G. He, J. Zhang, Y. Hu, Z. Bai, C. Wei, Appl. Catal. B Environ. 2019, 250, 301.

[4] B. Ni, H. Liu, P. Wang, J. He, X. Wang, Nat. Commun. 2015, 6, 8756.

[5] A. Ziarati, A. Badiei, R. Luque, Appl. Catal. B Environ. 2018, 238, 177.

[6] H. Eskandarloo, M. Zaferani, A. Kierulf, A. Abbaspourrad, Appl. Catal. B Environ. 2018, 227, 519.

[7] C. Worathitanon, K. Jangyubol, P. Ruengrung, W. Donphai, W. Klysubun, N. Chanlek, P. Prasitchoke, M. Chareonpanich, Appl. Catal. B Environ. 2019, 241, 359.

[8] D. Su, X. Zhang, A. Wu, H. Yan, Z. Liu, L. Wang, C. Tian, H. Fu, NPG Asia Mater. 2019, 11, 78.

[9] H. Wang, X. Liu, S. Wang, L. Li, Appl. Catal. B Environ. 2018, 222, 209.

[10] J. Fang, C. Kang, L. Fu, S. Li, Q. Liu, J. Alloys Compd. 2020, 849, 156317.

[11] K. Hu, F. Wang, Z. Shen, H. Liu, J. Xiong, J. Alloys Compd. 2021, 850, 156663.

[12] J. Lu, Y. Xie, F. Luo, H. Fu, X. Huang, Y. Liu, H. Liu, J. Alloys Compd. 2020, 844, 155788.

[13] X. Lai, J. E. Halpert, D. Wang, Energy Environ. Sci. 2012, 5, 5604

[14] X. Wang, J. Feng, Y. Bai, Q. Zhang, Y. Yin, Chem. Rev. 2016, 116, 10983.

[15] F. Kayaci, S. Vempati, C. Ozgit-Akgun, I. Donmez, N. Biyikli, T. Uyar, Appl. Catal. B Environ. 2015, 176-177, 646.

[16] A. Celebioglu, S. Vempati, C. Ozgit-Akgun, N. Biyikli, T. Uyar, RSC Adv. 2014, 4, 61698.

[17] T. Li, B. Xue, B. Wang, G. Guo, D. Han, Y. Yan, A. Dong, J. Am. Chem. Soc. 2017, 139, 12133.

[18] Y. Dong, B. Jia, F. Fu, H. Zhang, L. Zhang, J. Zhou, Angew. Chem. Int. Ed. 2016, 55, 13504

[19] S. Anitha, D. J. Thiruvadigal, T. S. Natarajan, Mater. Lett. 2011, 65, 167.

[20] A. Senthamizhan, B. Balusamy, Z. Aytac, T. Uyar, CrystEngComm, 2016, 18, 6341.

[21] H. Hou, M. Shang, L. Wang, W. Li, B. Tang, W. Yang, Sci. Rep. 2015, 5, 15228.

[22] L. Yu, W. Chen, D. Li, J. Wang, Y. Shao, M. He, P. Wang, X. Zheng, Appl. Catal. B Environ. 2015, 164, 453.

[23] Z. Li, J. Zhang, B. Guan, D. Wang, L.M. Liu, X. W. D. Lou, Nat. Commun. 2016, 7, 13065 .

[24] P. P. Das, A. Roy, M. Tathavadekar, P. S. Devi, Appl. Catal. B Environ. 2017, 203, 692

[25] J. Xue, T. Wu, Y. Dai, Y. Xia, Chem. Rev. 2019, 119, 5298.

[26] S. Peng, L. Li, Y. Hu, M. Srinivasan, F. Cheng, J. Chen, S. Ramakrishna, ACS Nano 2015, 9, 1945.

[27] M. Wang, L. Cui, S. Li, Z. Li, T. Ma, G. Luan, W. Liu, F. Zhang, RSC Adv. 2016, 6, 58452.

[28] J. Qiao, D. Xu, L. Lv, X. Zhang, F. Wang, W. Liu, J. Liu, ACS Appl. Nano Mater. 2018, 1, 5297.

[29] J. Fu, J. Zhang, Y. Peng, C. Zhao, Y. He, Z. Zhang, X. Pan, N. J. Mellors, E. Xie, Nanoscale 2013, 5, 12551.
[30] C. Niu, J. Meng, X. Wang, C. Han, M. Yan, K. Zhao, X. Xu, W. Ren, Y. Zhao, L. Xu, Q. Zhang, D. Zhao, L. Mai, Nat. Commun. 2015, 6, 7402.

[31] Y. Cheng, B. Zou, C. Wang, Y. Liu, X. Fan, L. Zhu, Y. Wang, H. Ma, X. Cao, CrystEngComm 2011, 13, 2863.

[32] L. Xu, R. Zheng, S. Liu, J. Song, J. Chen, B. Dong, H. Song, Inorg. Chem. 2012, 51, 7733

[33] J. T. Korhonen, P. Hiekkataipale, J. Malm, M. Karppinen, O. Ikkala, R. H. A. Ras, ACS Nano 2011, 5, 1967.

[34] J. Wu, D. Zeng, X. Wang, L. Zeng, Q. Huang, G. Tang, C. Xie, Langmuir 2014, 30, 11183.

[35] H. Tianou, W. Wang, X. Yang, Z. Cao, Q. Kuang, Z. Wang, Z. Shan, M. Jin, Y. Yin, Nat. Commun. 2017, 8, 1261.

[36] S. Peng, F. Gong, L. Li, D. Yu, D. Ji, T. Zhang, Z. Hu, Z. Zhang, S. Chou, Y. Du, S. Ramakrishna, J. Am. Chem. Soc. 2018, 140, 13644.

[37] H. Chen, K. Shen, Y. Tan, Y. Li, ACS Nano 2019, 13, 7800.

[38] S. S. Mali, H. Kim, W. Y. Jang, H. S. Park, P. S. Patil, C. K. Hong, ACS Sustain. Chem. Eng. 2013, 1, 1207.

[39] S. Dilger, M. Wessig, M. R. Wagner, J. S. Reparaz, C. M. S. Torres, L. Qijun, T. Dekorsy, S. Polarz, Cryst. Growth Des. 2014, 14, 4593.

[40] Q. P. Zhang, X. N. Xu, Y. T. Liu, M. Xu, S. H. Deng, Y. Chen, H. Yuan, F. Yu, Y. Huang, K. Zhao, S. Xu, G. Xiong, Sci. Rep. 2017, 7, 46424.

[41] W. Wang, M. Dahl, Y. Yin, Chem. Mater. 2013, 25, 1179.

[42] Z. Pei, L. Ding, J. Hu, S. Weng, Z. Zheng, M. Huang, P. Liu, Appl. Catal. B Environ. 2013, 142-143, 736.

[43] T. J. Penfold, J. Szlachetko, F. G. Santomauro, A. Britz, W. Gawelda, G. Doumy, A. M. March, S. H. Southworth, J. Rittmann, R. Abela, M. Chergui, C. J. Milne, Nat. Commun. 2018, 9, 478.

[44] Y. Jin, J. Long, X. Ma, T. Zhou, Z. Zhang, H. Lin, J. Long, X. Wang, Appl. Catal. B Environ. 2019, 256, 117873.

[45] J. Wang, Y. Xia, Y. Dong, R. Chen, L. Xiang, S. Komarneni, Appl. Catal. B Environ. 2016, 192, 8.

[46] S. Mukhopadhyay, P. P. Das, S. Maity, P. Ghosh, P. S. Devi, Appl. Catal. B Environ. 2015, 165, 128

[47] J. Liu, Z.Y. Hu, Y. Peng, H. W. Huang, Y. Li, M. Wu, X. X. Ke, G. V. Tendeloo, B. L. Su, Appl. Catal. B Environ. 2016, 181, 138.

[48] H. Zeng, G. Duan, Y. Li, S. Yang, X. Xu, W. Cai, Adv. Funct. Mater. 2010, 20, 561

[49] C. H. Ahn, Y. Y. Kim, D. C. Kim, S. K. Mohanta, H. K. Cho, J. Appl. Phys. 2009, 105, 013502.

[50] B. X. Lin, Z. X. Fu, Y. Jia, Appl. Phys. Lett. 2001, 79, 943.

[51] A. Wang, L. Zhang, M. G. Rahimi, S. Gong, L. Nie, N. Han, Y. Chen, Appl. Catal. B Environ. 2020, 277, 119223.

[52] R. Shwetharani, H. R. Chandan, M. Sakar, G. R. Balakrishna, K. R. Reddy, A. V. Raghu, Int. J. Hydrogen Energy 2020, 45, 18289.

[53] X. Liang, P. Wang, Y. Gao, H. Huang, F. Tong, Q. Zhang, Z. Wang, Y. Liu, Z. Zheng, Y. Dai, B. Huang, Appl. Catal. B Environ. 2020, 260, 118151.

[54] Y. Wei, Z. Zhou, W. H. Fang, R. Long, J. Phys. Chem. Lett. 2018, 9, 5884.

[55] K. R. Reddy, K. V. Karthik, S. B. B. Prasad, S. K. Soni, H. M. Jeong, A. V. Raghu, Polyhedron 2016, 120, 169.

[56] Q. Li, X. Tang, Y. Sun, Y. Wang, Y. Long, J. Jiang, H. Xu, RSC Adv. 2015, 5, 25337 